\title{
Characterization of "Pyomelanin"-Producing Strains of Pseudomonas aeruginosa
}

\author{
EIKO YABUUCHI and A. OHYAMA \\ Kansai Medical School, Department of Microbiology, Moriguchi-city, Osaka, Japan
}

\begin{abstract}
Forty strains of Pseudomonas aeruginosa (Schroeter) Migula isolated from clinical specimens and producing a water-soluble brown pigment on peptone media were compared with the neotype and nine other non-brown strains of $P$. aeruginosa. The brown pigment is formed from either tyrosine or phenylalanine through the accumulation of homogentisic acid and has no identity with DOPA melanin. A new term, "pyomelanin," is proposed for this brown pigment synthesized by certain strains of $P$. aeruginosa. Although the pyomelanin strains share the attributes of the species, some of them have a more limited capacity with regard to certain biochemical reactions than the neotype strain of $P$. aeruginosa. A careful examination is required to identify these aberrant strains. Actively growing cells of pyomelanin strains converted tyrosine to pyomelanin, but tyrosine itself does not appear to serve as a sole source of carbon and nitrogen for growth. A simple method of differentiating pyomelanin-producing strains of $P$. aeruginosa from pyorubin-producing strains is presented. To recognize properly the species, the attributes of pyomelanin strains should be included in descriptions of $P$. aeruginosa.
\end{abstract}

A water-soluble, brown pigment-producing bacterium was isolated in 1897 by Cassin (3) from a gummatous leg ulcer of a French cavalryman. Radais (36) described this bacterium as a "nouvelle race de la bacille pyocyanique" which produced a black-brown pigment in bouillon and peptone solutions. Gessard (9-11) included Cassin's strain in a study of pigment production by Pseudomonas aeruginosa (Schroeter) Migula and noted that the brown pigment was produced in the presence of ty rosine.

King et al. (25) observed that 3 of their 107 strains of $P$. aeruginosa produced a dark brown pigment on 6 different media within 18 to 24 hr. Later King (24) studied 34 brownpigmented strains which were identified as $P$. aeruginosa. A brown-pigmented, nonmotile strain of $P$. aeruginosa was isolated by Inoue $(20,21)$ from the blood of a patient with septicemia accompanied by candidiasis. Although this organism failed to produce pyocyanin on glycerol agar medium, typical pyocyanin producers were very easily isolated from a thigh-skin ulcer and an ear discharge of the same patient. In a study of acid production from carbohydrates by pseudomonads, Simon (39) included three strains of $P$. aeruginosa which corresponded with Gessard's race MA. According to Gessard (11), the organism of race MA produced brown pigment in peptone solution and a fluorescent, blue-green pigment, now called pyoverdin (4), in bouillon. Liu (28) isolated from the urine of a patient with chronic pyelonephritis and kidney stone a nonmotile, gram-negative rod which produced a melanin-like pigment on nutrient agar and identified it as a variant of $P$. aeruginosa by serological methods utilizing the extracellular antigens of the species. Elston (5) studied 16 melanin producers among 612 strains of $P$. aeruginosa isolated from biological specimens and called attention of bacteriologists and technologists to such strains. A preliminary report on the properties of brown-pigmented strains of $P$. aeruginosa was presented previously in order to stimulate awareness of such strains (42). Hugh (17) briefly referred to the attributes of brown-pigmented strains in his description of $P$. aeruginosa.

The water-soluble pigments synthesized by $P$. aeruginosa are called pyocyanin, pyorubin, and pyoverdin. As a matter of convenience, the term "pyomelanin" is proposed for the watersoluble, brown pigment produced by $P$. aeruginosa from tyrosine or phenylalanine; the term 
"apyomelanin" would then refer to the absence of pyomelanin.

In this paper a detailed study of the morphological, physiological, and biochemical characters of 40 pyomelanin-producing $P$. aeruginosa strains is presented.

\section{MATERIALS AND METHODS}

Bacterial strains. The histories and corresponding numbers of 40 pyomelanin and 10 apyomelanin strains of $P$. aeruginosa are listed in Tables 1 and 2, respectively.

The nine apyomelanin strains other than the neotype $($ KM 274 $=$ ATCC $10145=$ NCTC $10332=$ $\mathrm{RH} 815$ ) were selected for the following reasons: KM 205 produces pyocyanin and pyoverdin; KM 232 produces pyocyanin, pyorubin, and pyoverdin but is nonmotile; KM 306 received as probably Gessard's original strain produces pyoverdin but not pyocyanin; KM $325,326,327$, and 330 produce no pyocyanin, no pyorubin, and no pyoverdin; and KM 352 and 360 produce pyorubin and pyoverdin but not pyocyanin.

TABLE 1. Histories and corresponding strain numbers of 40 pyomelanin strains of Pseudomonas aeruginosa ${ }^{a}$

\begin{tabular}{|c|c|c|c|c|c|}
\hline KM & ATCC & RH & Other & Source & Received from \\
\hline 117 & 23993 & 1711 & & Blood & Inoue \\
\hline 233 & 23994 & 1419 & & Sputum & Hugh \\
\hline 255 & 23268 & 2528 & $\begin{array}{l}\text { Gessard MF, NCTC } 10780 \text {, } \\
\text { CCTM A17 }\end{array}$ & Leg ulcer & Buttiaux \\
\hline 256 & 23267 & 2583 & $\begin{array}{l}\text { Gessard MS, NCTC 10781, } \\
\text { CCTM A18 }\end{array}$ & Leg ulcer & Buttiaux \\
\hline 257 & 23996 & 1712 & Liu 1184 & Urine & Liu \\
\hline 272 & 23997 & 2409 & & Appendix & Hugh \\
\hline 273 & 23998 & 2537 & & Urine & Hugh \\
\hline 303 & 23999 & & Matsumoto Ps-29 & Urine & Matsumote \\
\hline 350 & 25000 & 2682 & & Urine & Branson \\
\hline 357 & 25001 & 2684 & Simon 238R & & Simon \\
\hline 374 & 25002 & 2686 & Matsumoto 3917 & Urine & Matsumoto \\
\hline 386 & & & Matsumoto Ps-48 & & Matsumoto \\
\hline 400 & & 2693 & & Urine & Hugh \\
\hline 419 & & & & Sputum & Branson \\
\hline 432 & & & Habs $6477 / 66$ & Urine & Habs \\
\hline 433 & & & Habs $6714 / 66$ & Urine & Habs \\
\hline 434 & & & Habs 06763/66 & Urine & Habs \\
\hline 435 & & & Habs F7/67 & Urine & Habs \\
\hline 436 & & & Habs Col 18/67 & Urine & Habs \\
\hline 437 & & & Habs $763 / 67$ & Urine & Habs \\
\hline 438 & & & Habs $04293 / 67$ & Wound & Habs \\
\hline 439 & & & $\begin{array}{r}\text { Habs } 4457 / 67, \\
\text { NCTC } 10782\end{array}$ & Urine & Habs \\
\hline 440 & & & Habs $0478 / 66$ & Urine & Habs \\
\hline 441 & & & Habs $4959 / 67$ & Urine & Habs \\
\hline 442 & & & Habs $07476 / 67$ & Urine & Habs \\
\hline 443 & & & Habs $09744 / 67$ & Urine & Habs \\
\hline 658 & & 2817 & NCTC 10783 & Respiratory tract & Goto \\
\hline 678 & & & & Urine & Wada \\
\hline 727 & & & CDC 6839 & Sputum & Weaver \\
\hline 728 & & & CDC 6874 & Urine & Weaver \\
\hline 729 & & & CDC 7103(1) & Urine & Weaver \\
\hline 730 & & & CDC 7360 & Urine & Weaver \\
\hline 731 & & & CDC 8147 & $\begin{array}{l}\text { Tracheal } \\
\text { secretion }\end{array}$ & Weaver \\
\hline 732 & & & CDC 8362(1) & Urine & Weaver \\
\hline 733 & & & CDC 9009 & Urine & Weaver \\
\hline 735 & & & CDC A131, NCTC 10784 & Urine & Weaver \\
\hline 736 & & & CDC A529(1) & Sputum & Weaver \\
\hline 760 & 19582 & & NCTC 6749, NRRL B-997 & Urine & Lapage, Haynes \\
\hline 873 & & & & & von Graevenitz \\
\hline 901 & & & & Urine & Wada \\
\hline
\end{tabular}

${ }^{a}$ Abbreviations: ATCC, American Type Culture Collection, Maryland; CCTM, Centre de Collection de Type Microbienne, Lille; CDC, Center for Disease Control, Atlanta; KM, Kansai Medical School Culture Collection, Osaka; NRRL, Northern Ultilization Research and Development Division, Peoria; RH, Rudolph Hugh, George Washington University, Washington, D.C.; NCTC, National Collection of Type Cultures, London. 
TABLE 2. Histories and corresponding strain numbers of 10 apyomelanin strains of Pseudomonas aeruginosa ${ }^{a}$

\begin{tabular}{llrlll}
\hline KM & ATCC & RH & Other & Status & Received from \\
\hline 205 & & & & & Matsubara \\
232 & 19424 & 1019 & NCTC 6750 & Hugh \\
274 & 10145 & 815 & NCTC 10332 & Neotype & Hugh \\
306 & 25010 & 2681 & CCTM A9 & Buttiaux \\
325 & & & PJ 106, Habs 0-6 & Jessen, Caselitz \\
326 & & & PJ 337 & Jessen \\
327 & \multirow{2}{*}{146} & PJ 350 & Jessen \\
330 & 17434 and 256 ${ }^{b}$ & 146 & NRR B-248 & Haynes, Hugh \\
352 & & 2683 & Stanier 57 & Stanier \\
360 & 25011 & 2685 & Simon 35R 4006 & Simon \\
\hline
\end{tabular}

${ }^{a}$ See Table 1 for abbreviations.

$b$ Two ATCC numbers for the same strain (H. D. Hatt, personal communication).

Morphology. The 18-hr Brain Heart Infusion (BHI; Difco) broth culture was formalinized, washed twice with distilled water, and stained for flagella $(26,27)$.

Physiology. Motility medium (17) was used in an attempt to demonstrate spreading in semisolid medium. Wet-mount preparations were used to detect motility in 18-hr broth cultures incubated at $20 \mathrm{C}$. Discrete colonies on infusion agar (Difco 0045) plates were examined for colonial morphology after 24, 48, and $72 \mathrm{hr}$. The ability to grow in BHI broth at $41 \mathrm{C}$ and $4 \mathrm{C}$ and at $p \mathrm{H} 4.5$ was tested. Plates of Leifson's deoxycholate (LD) agar, Salmonella-Shigella (SS) agar, nalidixic acid cetrimide (NAC) agar (1), and Pseudosel agar (BBL) were tested for growth at $30 \mathrm{C}$.

Biochemical reactions. Indophenol oxidase activity was tested as described by Ewing and Johnson (7). Modified Kovacs' reagent (8) was used to detect indole in $1 \%$ tryptone broth. Three per cent hydrogen peroxide solution was added to 24 -hr growth on infusion agar to detect catalase synthesis. Nutrient gelatin (Difco) was incubated at $20 \mathrm{C}$. A modification of the method of Moore and Pickett (17) for the production of 2-ketogluconate; the phenylalanine deaminase test by Ewing et al. (6); hydrolysis of Tween 80 by Sierra (38); Simmons citrate, $0.2 \%$ potassium nitrate broth with Durham tube (17); decarboxylase base M $\phi$ ller (33) (Difco 0890); ninhydrin test by Carlquist (2) to detect lysine decarboxylase; acetamide broth by Arai et al. (1) for acylamidase test; and deoxyribonucleic acid (DNA) agar for deoxyribonuclease activity were used. Lead acetate paper was suspended over Kligler's iron agar slant to detect hydrogen sulfide. The effects of the bacteria on 26 carbohydrates were determined in oxidative-fermentative (OF) basal medium described by Hugh and Leifson (18) (Difco 0688). Media were prepared as described by Hugh and Reese (19).

Ability to produce the specific phenazine pigments pyocyanin and pyorubin was determined on slants of pseudomonas agar P (Difco 0449). Pseudomonas agar F (Difco 0448) was used for the detection of pyoverdin. Slants of glutamic acid medium (34) were used for pyoverdin and other fluorescent substances. Infusion agar (Difco 0045) was used to detect the water-soluble brown pigment, pyomelanin.
Growth and pigment production on amino acid or carbohydrate media, or on both. The effects of 16 amino acids and 13 carbohydrates on the growth and pigment production of 50 strains were tested on the following media, all of which, when uninoculated, were colorless in daylight and nonfluorescent under ultraviolet light

(i) Amino acid media. A single amino acid or related nitrogen compound was added in a $1 \%$ concentration to a basal medium (34) as the sole source of carbon and nitrogen. The medium was dispensed in test tubes, autoclaved at $116 \mathrm{C}$ for 10 min, and allowed to solidify as a slant. Basal medium $\left(p \mathrm{H}\right.$ 7.0) contained: $\mathrm{KH}_{2} \mathrm{PO}_{4}, 2.0 \mathrm{~g} ; \mathrm{NaCl}, 5.0 \mathrm{~g}$; $\mathrm{MgSO}_{4} \cdot 7 \mathrm{H}_{2} \mathrm{O}, 0.1 \mathrm{~g}$; agar, $15.0 \mathrm{~g}$; and distilled water, $1,000 \mathrm{ml}$.

The following 16 organic nitrogen compounds, able to support the growth of apyomelanogenic $P$. aeruginosa strains as a sole source of carbon and nitrogen (39), were used: L- $\alpha$-alanine, $\beta$-alanine, $\gamma$-amino- $n$ butyric acid, L-arginine, L-aspartic acid, L-glutamic acid, L-glycine, L-histidine, L-leucine, L-lysine, Lornithine, L-phenylalanine, L-proline, L-tryptophan, L-tyrosine, and L-valine.

(ii) Carbohydrate media. The 13 carbohydrates oxidized by 10 apyomelanin strains with acid production in the OF medium were selected as carbon sources. A membrane-filtered $10 \%$ solution of each of the following carbohydrates-D-arabinose, L-arabinose, fructose, galactose, glucose, glycine, mannitol, mannose, melibiose, D-ribose, trehalose, and xylosewas aseptically added to the autoclaved and cooled basal medium containing $0.5 \%$ ammonium sulfate, making a final carbohydrate concentration of $1 \%$. Sterile $30 \%$ ethanol was added to give a final concentration of $3 \%$. Indicator was not added because acidity detection was not required. Each medium was aseptically dispensed and allowed to solidify in a slanted position.

Although a low concentration of nitrogen compounds, such as $0.1 \%$, is sufficient to determine the nutritional requirements of organisms $(40)$, it is inadequate for pigment production. Hence amino acids and related compounds were used in a $1 \%$ concentration, which effectively stimulates pigmenta- 
tion. Carbohydrates were also used in $1 \%$ concentrations.

(iii) Media for pyomelanin production. In an attempt to observe pyomelanin production, 1 liter of each of the above-described amino acid and carbohydrate media was supplemented with $2 \mathrm{~g}$ of either L-tyrosine or L-phenylalanine, the amino acids having been added before autoclaving. The medium was dispensed and solidified in a slanted position.

Organisms harvested from a 24-hr infusion agar culture were suspended in sterile, distilled water at a concentration of $10^{8}$ cells $/ \mathrm{ml}$ and were used as the inoculum. The medium, inoculated by a needle, was incubated for 5 days at $30 \mathrm{C}$ and later at room temperature. Cultures were observed daily for 2 weeks. The glutamate-ty rosine-agar slant was heavily inoculated from a $24-\mathrm{hr}$ slant culture for the prompt differentiation of pyomelanin from pyorubin, incubated at $37 \mathrm{C}$, and examined for pigment production after 2,4 , and $24 \mathrm{hr}$.

Sensitivities to antibiotics. The antibiotic sensitivities of 40 pyomelanin and 10 apyomelanin strains were estimated by the agar-disc diffusion technique. A 40-ml amount of sterile melted blood-agar base medium (Difco 0045) was cooled to about $45 \mathrm{C}$, and $0.2 \mathrm{ml}$ of a $24-\mathrm{hr}$ BHI broth culture was added. The mixture was then equally distributed between two petri dishes (9-cm diameter). Six 8-mm antibiotic discs (Showa Yakuhin Kako, Tokyo) were applied on each plate. The diameters of the inhibition zones including the disc diameter were measured after incubation for $18 \mathrm{hr}$ at $30 \mathrm{C}$. The degree of sensitivity was expressed as,,-+++ , or +++ (see Table 10 ) according to the manufacturer's statement (see Table 9).

\section{RESULTS}

Morphology. All 50 pyomelanin and apyomelanin strains were gram-negative, asporogenous rods. Motile strains contained many cells with one flagellum, a few cells with two flagella at one pole, and some cells with no flagella. Liu's strain 1184 (KM 257) contained some cells with a polar monotrichous flagellum similar to that of the neotype strain of $P$. aeruginosa. Strain KM 256 had an unusually long, single, polar flagellum (Fig. 1). The length of the flagellum was often seven times that of the soma. The wavelength and amplitude of the flagellum of KM 256, but not its length, appear to be similar to those of the neotype strain.

Physiology and biochemistry. The physiology and biochemistry of the strains tested are summarized in Tables 3 and 4 . With the exception of 2 pyomelanin producers, all 50 strains grew in BHI broth at $41 \mathrm{C}$ and all failed to grow at $4 \mathrm{C}$. No visible turbidity developed at 30 or $37 \mathrm{C}$ in $\mathrm{BHI}$ broth adjusted to $p \mathrm{H} 4.5$.

On infusion agar, pyomelanin strains produced small, circular, translucent colonies with

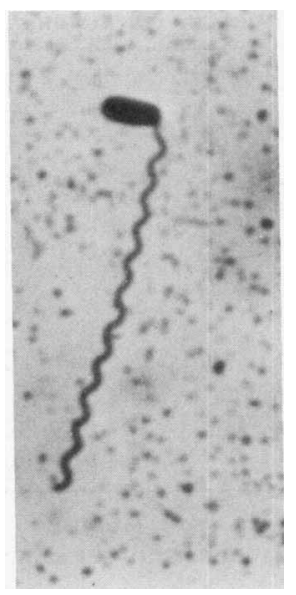

FIG. 1. Pseudomonas aeruginosa KM 256 showing a long, polar flagellum, typical for this strain. Leifson flagella stain $(26,27) . \times 1,500$.

an almost entire edge in $24 \mathrm{hr}$, and a heavily inoculated portion of the plate became a characteristic coffee-brown color. As the cultures aged, the entire plate became coffeebrown, the colonies increased in size, and the brown color appeared at the colony center. Large, spreading, grayish colonies with dark centers and translucent irregular edges, typical of the colonial morphology of $P$. aeruginosa (16), were not seen in most of the 40 pyomelanin-producing strains.

Both pyomelanin and apyomelanin strains grew on LD, NAC, and Pseudosel agars and in $3 \% \mathrm{NaCl}$ broth; produced indophenol oxidase, catalase, 2-ketogluconate, gas from nitrate, arginine dihydrolase, and acylamidase; and utilized citrate and malonate. An anaerogenic and oxidative acid reaction was produced in open tubes of OF basal medium containing D-arabinose, L-arabinose, ethanol, fructose, galactose, glucose, glycerol, mannitol, D-ribose, trehalose, and xylose. Thirty pyomelanin strains $(75 \%)$ failed to produce acid from mannose, 32 strains $(80 \%)$ did not produce acid from melibiose, and 19 strains $(47.5 \%)$ failed to produce acid from galactose. The attributes of six pyomelanin strains which were negative in certain reactions useful for the identification of $P$. aeruginosa are listed in Table 5 and are compared with the characteristics of the neotype.

All 50 strains did not produce indole, acid in methyl red broth, acetyl methyl carbinol, hydrogen sulfide, amylase, decarboxylase for lysine and ornithine at $p \mathrm{H} 6.5$ to 7.5 , or phenylalanine deaminase. There was no acid 
TABLE 3. Characteristics of Pseudomonas aeruginosa

\begin{tabular}{|c|c|c|c|}
\hline \multirow[b]{2}{*}{ Morphology, substrate, or test ${ }^{a}$} & \multicolumn{2}{|c|}{ Present study } & \multirow[b]{2}{*}{$\begin{array}{c}\text { Hugh, } 1970^{d} \\
(\%+)\end{array}$} \\
\hline & $\begin{array}{c}\text { Pyomelanin-producing } \\
\text { strains }^{b} \\
(\%+)^{e}\end{array}$ & $\begin{array}{l}\text { Apyomelanin } \\
\text { strains } s^{c} \\
(\%+)\end{array}$ & \\
\hline Gram-negative, rod-shaped $\ldots \ldots \ldots$ & 100 & 100 & 100 \\
\hline Motility $\ldots \ldots \ldots \ldots \ldots$ & 90 & 90 & 93 \\
\hline Polar monotrichous $\ldots \ldots \ldots \ldots$ & 90 & 90 & 93 \\
\hline Growth in $\mathrm{BHI}$ at $41 \mathrm{C} \ldots \ldots \ldots$ & 95 & 100 & 100 \\
\hline Growth in BHI at $4 \mathrm{C}$. & 0 & 0 & \\
\hline Growth in BHI at $p \mathrm{H} 4.5 \ldots \ldots$ & 0 & 0 & \\
\hline Growth on $L D$ agar $\ldots \ldots \ldots \ldots$ & 100 & 100 & 100 \\
\hline Growth on $S S$ agar $\ldots \ldots \ldots \ldots \ldots \ldots$ & 95 & 100 & 100 \\
\hline Growth on NAC agar $\ldots \ldots \ldots \ldots$ & 97.5 & 100 & \\
\hline Growth on Pseudosel agar & 100 & 100 & \\
\hline Indophenol oxidase, catalase $\ldots \ldots$ & 100 & 100 & 100 \\
\hline $\mathrm{H}_{2} \mathrm{~S}$, Kligler butt and paper $\ldots \ldots$ & 0 & 0 & \\
\hline Simmons citrate $\ldots \ldots \ldots \ldots$ & 95 & 100 & 100 \\
\hline Gas from nitrate $\ldots \ldots \ldots \ldots \ldots$ & 97.5 & 100 & 94 \\
\hline Nitrite test in nitrate broth . . & 2.5 & 0 & \\
\hline Malonate utilization $\ldots \ldots \ldots \ldots$ & 92.5 & 100 & \\
\hline Urea, Christensen . . . . . . . . . & 77.5 & 100 & 23 \\
\hline Carlquist ninhydrin $\ldots$. & 0 & 0 & 0 \\
\hline L-Lysine decarboxylase, Mфller & 0 & 0 & 0 \\
\hline L-Arginine dihydrolase, M $\phi$ ller . . . . . & $90(5)$ & 100 & $96(3)$ \\
\hline L-Ornithine decarboxylase, M $\phi$ ller . . & 0 & 0 & 0 \\
\hline Phenylalanine deaminase $\ldots \ldots \ldots$ & 0 & 0 & \\
\hline Acylamidase $\ldots \ldots \ldots \ldots \ldots$ & 100 & 100 & \\
\hline 2-Ketogluconate $\ldots \ldots \ldots \ldots \ldots$ & 90 & 100 & 100 \\
\hline Liquefaction of gelatin & $62.5(32.5)$ & 100 & $80(19)$ \\
\hline Hydrolysis of Tween $80 \ldots \ldots \ldots$ & $97.5(2.5)$ & $83(17)$ & \\
\hline Pyocyanin in pseudomonas $\mathrm{P}$ agar & 60 & 50 & $58^{f}$ \\
\hline Pyorubin in pseudomonas $\mathbf{P}$ agar ... & 0 & 30 & \\
\hline Pyoverdin in pseudomonas $\mathrm{F}$ agar & 67.5 & 60 & \\
\hline Pyomelanin in blood-agar base ... & 100 & 0 & \\
\hline
\end{tabular}

${ }^{a}$ Abbreviations: BHI, Brain Heart Infusion; LD agar, Leifson deoxycholate agar; SS agar, Salmonella-Shigella agar; NAC agar, nalidixic acid-cetrimide agar.

$b$ Forty strains tested.

$c$ Ten strains tested.

d One hundred eighteen strains tested.

$e$ Values indicate per cent positive within 1 or 2 days. Values in parentheses indicate per cent positive, delayed 3 or more days.

$f$ Result on blood-agar base medium.

reaction in open tubes of OF medium with adonitol, cellobiose, dulcitol, inositol, inulin, lactose, maltose, melezitose, raffinose, salicin, or sorbitol. An acid reaction was not produced in OF glucose medium sealed with stiff petrolatum.

The pyomelanin strains produced a brown diffusible pigment on infusion agar and pseudomonas $\mathrm{P}$ agar slant within 24 to $48 \mathrm{hr}$. Twenty-four of the 40 pyomelanin strains $(60 \%)$ produced various amounts of pyocyanin on pseudomonas agar $P$, but pyorubin could not be detected because of browning of the medium. Thirteen of the pyomelanin-producing strains $(32.5 \%)$ and four of the apyomelanin strains $(40 \%)$ failed to produce pyoverdin, a yellow-green fluorescent pigment, on pseudomonas agar F (Table 3). Of these 17 apyoverdin strains, 10 , grown on glutamic acid medium, showed a blue fluorescence under ultraviolet light, though the cultures were colorless in daylight.

Growth and pigment production on amino acid or carbohydrate media, or on both. In contrast to the apyomelanin strains, which showed $100 \%$ positive growth, only $2.5 \%$ of 40 pyomelanin strains were able to grow with leucine as the sole source of carbon and 
TABLE 4. Oxidative acid production from carbohydrates in $O F$ medium ${ }^{\alpha}$

\begin{tabular}{|c|c|c|c|c|}
\hline \multirow[b]{2}{*}{ Test } & \multicolumn{2}{|c|}{ Present study } & \multirow[b]{2}{*}{$\begin{array}{c}\text { Jessen, } 1965 \\
(\%+)\end{array}$} & \multirow[b]{2}{*}{$\begin{array}{c}\text { Hugh, } 1970 \\
(\%+)\end{array}$} \\
\hline & $\begin{array}{l}\text { Pyomelanin- } \\
\text { producing strains } \\
(\%+)^{b}\end{array}$ & $\begin{array}{l}\text { Apyomelanin } \\
\text { strains } \\
(\%+)\end{array}$ & & \\
\hline Adonitol . . . . . . . . & 0 & 0 & 0 & $9(3)$ \\
\hline D-Arabinose $\ldots \ldots \ldots$ & $80(12.5)$ & 100 & $91.2(8.8)$ & \\
\hline L-Arabinose $\ldots \ldots \ldots$ & $47.5(32.5)$ & 100 & $97.1(2.9)$ & $97(3)$ \\
\hline Cellobiose . . . . . . . & 0 & 0 & & $12(36)$ \\
\hline Dulcitol $\ldots \ldots \ldots \ldots$ & 0 & 0 & 0 & 0 \\
\hline Ethanol $(3 \%) \ldots \ldots \ldots$ & $40(50)$ & $70(30)$ & $70(30)$ & $67(29)$ \\
\hline Fructose $\ldots \ldots \ldots \ldots$ & $82.5(2.5)$ & $80(20)$ & & $69(22)$ \\
\hline Galactose ....... & $15(37.5)$ & 100 & & $97(2)$ \\
\hline Glucose $\ldots \ldots \ldots$. & $92.5(5)$ & 100 & 100 & 100 \\
\hline Glycerol . . . . . . . . . & $80(10)$ & 100 & $83.3(16.7)$ & \\
\hline Inositol $\ldots \ldots \ldots \ldots$ & 0 & 0 & 0 & $12(2)$ \\
\hline Inulin $\ldots \ldots \ldots \ldots \ldots$ & 0 & 0 & & 0 \\
\hline Lactose $\ldots \ldots \ldots \ldots$ & 0 & 0 & $0(2.2)$ & $0(35)$ \\
\hline Maltose ............ & 0 & 0 & $0(0.2)$ & 0 \\
\hline Mannitol .......... & $85(2.5)$ & 100 & $83.8(14.4)$ & $81(11)$ \\
\hline Mannose . . . . . . . . & $17.5(7.5)$ & 100 & & $98(1)$ \\
\hline Melezitose $\ldots \ldots \ldots \ldots$ & 0 & 0 & $0^{c}$ & 0 \\
\hline Melibiose ..... & $10(10)$ & 100 & $36.5(63.5)^{c}$ & $75(22)$ \\
\hline Raffinose ... & 0 & 0 & 0 & 0 \\
\hline Rhamnose ..... & $2.5(5)$ & 0 & $0(79)$ & $6(70)$ \\
\hline D-Ribose $\ldots \ldots$ & $62.5(35)$ & 100 & & $96(4)$ \\
\hline Salicin .... & 0 & 0 & 0 & 0 \\
\hline Sorbitol .. & 0 & 0 & 0 & 0 \\
\hline Sucrose ... & 2.5 & 0 & 0 & $12(3)$ \\
\hline Trehalose .... & $22.5(52.5)$ & $30(30)$ & $10.4(64.1)$ & $17(43)$ \\
\hline Xylose ....... & $15(47.5)$ & 100 & $99.4(0.6)$ & $98(2)$ \\
\hline $\begin{array}{l}\text { OF basal medium, } \\
\text { control blue }\end{array}$ & 100 & 100 & & 100 \\
\hline
\end{tabular}

${ }^{a}$ Numbers of strains tested were: pyomelanin-producing, 40; apyomelanin, 10; Jessen, 354; Hugh, 118.

$b$ Values indicate per cent positive within 1 or 2 days. Values in parentheses indicate per cent positive, delayed 3 or more days.

${ }^{c}$ Based on a study of 41 strains.

nitrogen. No growth of pyomelanin strains occurred when either tyrosine or phenylalanine was added to the basal medium as a sole source of carbon and nitrogen. Furthermore, $85 \%$ of the pyomelanin-producing strains failed to grow on a tryptophan medium. The results are summarized in Table 6 and compared with the data of Stanier et al. (40). Some of the 40 pyomelanin-producing strains formed pyocyanin or pyoverdin or both on certain amino acid media, especially proline and $\gamma$-amino- $n$ butyric acid media. The four strains, KM 303, 438,443 , and 760 , grown on certain amino acid media synthesized a water-soluble red pigment, pyorubin, which could not be detected on pseudomonas agar P. All 40 strains, however, failed to produce a water-soluble brown pigment on any of the single amino acid media (Table 7). The tyrosine or phenylalanine medium, containing no other amino acid and inoculated with a pyomelanin-producing organism, became faint pink or pink after 3 or more days of incubation without showing any definite growth on the medium. The color of the medium remained pink, and no brown color appeared.

More than $90 \%$ of the pyomelanin-producing strains grew in the presence of fructose, galactose, glucose, and glycerol. Only $12.5 \%$ of 40 strains utilized melibiose and xylose, and 7.5\% utilized mannose. All apyomelanin strains showed growth on various carbohydrate media tested (Table 8). Not only pyomelanin but also phenazin pigments and pyoverdin were produced by none of the 50 strains on the single-carbohydrate media tested.

When pyomelanin-producing strains grew on the amino acid medium supplemented with either tyrosine or phenylalanine, both tyrosine and phenylalanine were converted to a water- 
TABLE 5. Dissimilar characteristics of six pyomelanin-producing Pseudomonas aeruginosa strains compared with the characteristics ${ }^{a}$ of the neotype strain (KM 274) of P. aeruginosa

\begin{tabular}{|c|c|c|c|c|c|c|c|}
\hline \multirow[b]{3}{*}{ Test } & \multicolumn{7}{|c|}{ KM strain no. } \\
\hline & \multirow[b]{2}{*}{$\begin{array}{c}\text { Neotype } \\
274\end{array}$} & \multicolumn{6}{|c|}{ Pyomelanin strains $^{b}$} \\
\hline & & 257 & 400 & 439 & 658 & 733 & 735 \\
\hline Glucose open & + & + & + & - & $t_{3}$ & + & $t_{2}$ \\
\hline D-Arabinose ... & + & + & - & + & + & $+t_{14}$ & $+t_{2}$ \\
\hline L-Arabinose $\ldots$ & + & + & - & + & + & $+t_{15}$ & $+_{3}$ \\
\hline Fructose ...... & + & + & - & - & + & - & - \\
\hline Mannitol ........ & + & - & - & - & + & - & - \\
\hline D-Ribose $\ldots \ldots$ & + & + & - & $\mathrm{wk}_{19}$ & + & $t_{13}$ & $t_{3}$ \\
\hline Simmons citrate & + & - & + & + & + & - & + \\
\hline 2-Ketogluconate & + & + & + & + & NG & NG & NG \\
\hline L-Arginine dihydrolase & + & - & + & + & - & + & + \\
\hline Growth at $41 \mathrm{C} \ldots \ldots$ & + & - & + & + & - & + & + \\
\hline Growth on SS agar & + & - & + & + & + & + & - \\
\hline Growth on NAC agar & + & + & + & + & + & - & + \\
\hline Pyocyanin ....... & + & wk & - & - & wk & - & - \\
\hline Pyoverdin ....... & + & - & - & + & wk & - & + \\
\hline
\end{tabular}

${ }^{\alpha}$ Characteristics useful for the identification of $P$. aeruginosa.

${ }^{b}$ NG, no growth; wk, weakly positive reaction. Subscripts indicate number of days required for a positive reaction.

TABLE 6. Growth with various amino acids $(1 \%)^{a}$

\begin{tabular}{|c|c|c|c|}
\hline \multirow[b]{2}{*}{ Substrate } & \multicolumn{2}{|c|}{ Present study } & \multirow[b]{2}{*}{$\begin{array}{c}\text { Stanier, } \\
1966 \\
(\%+)\end{array}$} \\
\hline & $\begin{array}{l}\text { Pyomelanin- } \\
\text { producing strains } \\
\qquad(\%+)^{c}\end{array}$ & $\begin{array}{c}\text { Apomyelanin } \\
\text { strains } \\
(\%+)\end{array}$ & \\
\hline$L-\alpha$-Alanine $\ldots \ldots \ldots \ldots \ldots \ldots$ & 92.5 & 100 & 100 \\
\hline$\beta$-Alanine $\ldots \ldots \ldots \ldots \ldots \ldots$ & 90 & 100 & 100 \\
\hline$\gamma$-Amino- $n$-buty ric acid $\ldots \ldots \ldots$ & 95 & 100 & 100 \\
\hline L-Arginine $\ldots \ldots \ldots \ldots \ldots$ & 97.5 & 100 & $100^{d}$ \\
\hline Aspartic acid $\ldots \ldots \ldots \ldots \ldots \ldots$ & 92.5 & 100 & 100 \\
\hline Glutamic acid $\ldots \ldots \ldots \ldots \ldots$ & 92.5 & 100 & 100 \\
\hline Glycine $\ldots \ldots \ldots \ldots$ & 45 & $10(90)$ & 75.8 \\
\hline Histidine ... & 92.5 & 100 & 100 \\
\hline L-Leucine $\ldots$ & 2.5 & 100 & 100 \\
\hline L-Lysine $\ldots$ & 55 & $80(20)$ & 89.7 \\
\hline L-Ornithine . . & 95 & 100 & $100^{d}$ \\
\hline Proline ........ & 95 & 100 & 100 \\
\hline L-Phenylalanine $\ldots \ldots \ldots$ & 0 & $30(40)$ & 24.1 \\
\hline L-Tryptophan $\ldots \ldots \ldots \ldots$ & 15 & 100 & 72.4 \\
\hline L-Tyrosine $\ldots \ldots \ldots \ldots \ldots \ldots$ & 0 & 100 & 89.6 \\
\hline L-Valine $\ldots \ldots \ldots \ldots$ & 62.5 & 100 & 86.2 \\
\hline
\end{tabular}

${ }^{a}$ Numbers of strains tested were: pyomelanin-producing, 40; apyomelanin, 10 ; Stanier, 29.

$b$ Substrates were used in concentration of $0.1 \%$.

${ }^{c}$ Values indicate per cent positive within 1 or 2 days. Values in parentheses indicate per cent positive, delayed 3 or more days.

${ }^{d}$ DL compound.

soluble brown pigment via a water-soluble, deep red or reddish purple substance within 24 to 48 hr. With the limited growth on lysine or valine medium, the color of medium remained somewhere between a faint pink and a deep red.
Strains which grew poorly on these media slowly turned the media brown after a prolonged period at room temperature. Pyomelanin strains promptly produced pyomelanin from tyrosine or phenylalanine on media 
TABLE 7. Pigment production of 40 pyomelanin strains on single amino acid media

\begin{tabular}{|c|c|c|c|c|}
\hline \multirow[b]{2}{*}{ Substrate } & \multicolumn{4}{|c|}{ Pigment } \\
\hline & $\begin{array}{c}\text { Pyocyanin } \\
(\%+)\end{array}$ & $\begin{array}{c}\text { Pyorubin } \\
(\%+)\end{array}$ & $\begin{array}{c}\text { Pyoverdin } \\
(\%+)\end{array}$ & $\begin{array}{c}\text { Pyomelanin } \\
(\%+)\end{array}$ \\
\hline L- $\alpha$-Alanine $\ldots \ldots \ldots \ldots \ldots$ & 7.5 & 7.5 & 35 & 0 \\
\hline$\ldots \ldots \ldots$ & 27.5 & 5 & 35 & 0 \\
\hline$\gamma$-Amino- $n$-butyric acid $\ldots \ldots \ldots$ & 30 & 2.5 & 57.5 & 0 \\
\hline L-Arginine & 2.5 & 0 & 20 & 0 \\
\hline Aspartic acid . . . . . . & 10 & 0 & 27.5 & 0 \\
\hline Glutamic acid $\ldots \ldots \ldots \ldots \ldots$ & 20 & 0 & 47.5 & 0 \\
\hline Glycine . . . . . . . . . & 0 & 2.5 & 0 & 0 \\
\hline Histidine $\ldots \ldots \ldots \ldots \ldots \ldots$ & 2.5 & 0 & 35 & 0 \\
\hline L-Leucine $\ldots \ldots \ldots \ldots \ldots$ & 0 & 0 & 0 & 0 \\
\hline L-Lysine $\ldots \ldots \ldots \ldots$ & 5 & 0 & 20 & 0 \\
\hline L-Ornithine $\ldots \ldots \ldots \ldots$ & 7.5 & 5 & 30 & 0 \\
\hline Proline $\ldots \ldots \ldots \ldots$ & 35 & 0 & 37.5 & 0 \\
\hline L-Tryptophan & 0 & 0 & 0 & 0 \\
\hline L-Valine $\ldots \ldots \ldots \ldots$ & 0 & 0 & 0 & 0 \\
\hline
\end{tabular}

TABLE 8. Growth with various carbohydrates $(1 \%)^{a}$

\begin{tabular}{|c|c|c|c|}
\hline \multirow[b]{2}{*}{ Substrate } & \multicolumn{2}{|c|}{ Present study } & \multirow[b]{2}{*}{$\begin{array}{c}\text { Stanier, } \\
1966 \\
(\%+)\end{array}$} \\
\hline & $\begin{array}{l}\text { Pyomelanin- } \\
\text { producing strains } \\
(\%+)^{c}\end{array}$ & $\begin{array}{l}\text { Apyomelanin } \\
\text { strains } \\
(\%+)\end{array}$ & \\
\hline D-Arabinose. & $10(32.5)$ & 90 & \\
\hline L-Arabinose $\ldots \ldots$ & $10(12.5)$ & 90 & \\
\hline Ethanol $\ldots \ldots \ldots$ & $15(15)$ & 100 & 100 \\
\hline Fructose $\ldots \ldots \ldots$ & 92.5 & 100 & 96.5 \\
\hline Galactose . . . . . . . . & $85(7.5)$ & 100 & \\
\hline Glucose $\ldots \ldots \ldots$ & $90(2.5)$ & 100 & 100 \\
\hline Glycerol . . . . . . . & $90(2.5)$ & 100 & 100 \\
\hline Mannitol ....... & $82.5(2.5)$ & 100 & 100 \\
\hline Mannose ...... & 7.5 & 90 & \\
\hline Melibiose . . . . . . & $7.5(5)$ & $60(20)$ & \\
\hline D-Ribose $\ldots \ldots \ldots$ & $42.5(12.5)$ & $90(10)$ & 100 \\
\hline Trehalose $\ldots \ldots \ldots \ldots \ldots$ & $27.5(55)$ & $60(10)$ & \\
\hline Xylose ............ & 12.5 & $70(10)$ & \\
\hline
\end{tabular}

\footnotetext{
${ }^{a}$ Numbers of strains tested were: pyomelanin-producing, 40; apyomelanin, 10 ; Stanier, 29.

$b$ Substrates were used in a concentration of $0.1 \%$.

$c$ Values indicate per cent positive within 1 or 2 days. Values in parentheses indicate per cent positive, delayed 3 or more days.
}

containing glutamic acid, aspartic acid, or L-arginine. There was no marked difference in the browning effect between L-tyrosine and L-phenylalanine. The synthesis of phenazin pigments and pyoverdin on certain amino acid media by pyomelanin-producing and apyomelanin strains did not appear to be affected by the addition of either tyrosine or phenylalanine. Although pyoverdin often became orange or bright brown, pyocyanin became very dark blue-green, and pyorubin became dark red or reddish brown on certain amino acid media as well as on pseudomonas agars after 7 or more days at room temperature; these pigmentations are distinguishable from the early coffee-brown pigmentation produced by pyomelanin-producing strains.

Differentiation of pyomelanin production from pyorubin production. Pyomelanogenic $P$. aeruginosa strains promptly produced the water-soluble brown pigment pyomelanin throughout the entire slant of glutamatetyrosine-agar. When the medium was heavily inoculated from a 24-hr infusion agar slant culture, a pink or red pigment appeared within $4 \mathrm{hr}$ at $37 \mathrm{C}$ and became deep brown within 24 
hr. Apyocyanogenic and apyomelanogenic pyorubin-producing strains produced a small quantity of pyoverdin alone in the first few hours of incubation, and a pink or red color appeared after 3 or more days.

Pyomelanin-producing strains, when inoculated on phenylalanine agar (Difco 0745), converted the phenylalanine to pyomelanin within $24 \mathrm{hr}$ instead of deaminating it. Pyorubin producers never made the medium pink or red within 24 to $48 \mathrm{hr}$ of incubation.

Sensitivity to antibiotics. The antibiotic sensitivity patterns of the 40 pyomelanin strains were similar to those of the apyomelanin ones, although the former were generally more sensitive (Tables 9 and 10).
Moles per cent of guanine plus cytosine. The moles per cent of guanine plus cytosine in the DNA of the five pyomelanin strains, as determined by $\mathbf{R}$. R. Colwell (personal communication), are given in Table 11 .

\section{DISCUSSION}

Although strains of $P$. aeruginosa which produce water-soluble brown pigments have been known for some time, detailed descriptions of such strains have rarely been made (15, 16, 22, 35, 40). Pyomelanogenic $P$. aeruginosa strains have sometimes been confused with apyomelanogenic $P$. aeruginosa strains which

TABLE 9. Showa discs: content of antibiotics and criteria for sensitivity determination

\begin{tabular}{|c|c|c|c|c|c|}
\hline \multirow[b]{2}{*}{ Antibiotic } & \multirow[b]{2}{*}{$\begin{array}{l}\text { Content } \\
\text { in one } \\
\text { disc }\end{array}$} & \multicolumn{4}{|c|}{$\begin{array}{c}\text { Degree of sensitivity } \\
\text { Diameter of inhibition zone }(\mathrm{mm})\end{array}$} \\
\hline & & - & + & ++ & +++ \\
\hline Ampicillin & $30 \mu \mathrm{g}$ & $<8$ & $9-15$ & $16-23$ & $>24$ \\
\hline Chloramphenicol & $100 \mu \mathrm{g}$ & $<12$ & $13-20$ & $21-27$ & $>28$ \\
\hline Colistin ....... & 150 units & $<8$ & $9-11$ & $12-14$ & $>15$ \\
\hline Erythromycin $\ldots$ & $50 \mu \mathrm{g}$ & $<11$ & $12-18$ & $19-23$ & $>24$ \\
\hline Gentamicin $\ldots$ & $30 \mu \mathrm{g}$ & $<10$ & $11-16$ & $17-23$ & $>24$ \\
\hline Kanamycin . & $50 \mu \mathrm{g}-$ & $<8$ & $9-15$ & $16-21$ & $>22$ \\
\hline Nalidixic acid & $50 \mu \mathrm{g}$ & $<8$ & $9-18$ & $19-26$ & $>27$ \\
\hline Novobiocin . & $20 \mu \mathrm{g}$ & $<11$ & $12-18$ & $19-24$ & $>25$ \\
\hline Penicillin .. & 20 units & $<8$ & $9-19$ & $20-30$ & $>31$ \\
\hline Polymy xin B & 100 units & $<8$ & $9-12$ & $13-15$ & $>16$ \\
\hline Streptomycin & $50 \mu \mathrm{g}$ & $<8$ & $9-15$ & $16-20$ & $>21$ \\
\hline Tetracycline. & $200 \mu \mathrm{g}$ & $<10$ & $11-17$ & $18-24$ & $>25$ \\
\hline
\end{tabular}

TABLE 10. Sensitivity to antibiotics

\begin{tabular}{|c|c|c|c|c|c|c|c|c|c|c|}
\hline \multirow[b]{3}{*}{ Antibiotic } & \multicolumn{5}{|c|}{ Pyomelanin-producing strains ${ }^{a}$} & \multicolumn{5}{|c|}{ Apyomelanin strains $b$} \\
\hline & \multicolumn{4}{|c|}{ No. of strains } & \multirow[b]{2}{*}{$\begin{array}{l}\text { Per cent } \\
\text { sensitive }\end{array}$} & \multicolumn{4}{|c|}{ No. of strains } & \multirow[b]{2}{*}{$\begin{array}{l}\text { Per cent } \\
\text { sensitive }\end{array}$} \\
\hline & - & + & ++ & +++ & & - & + & ++ & $+t+$ & \\
\hline Ampicillin & 31 & 4 & 4 & 1 & 22.5 & 10 & 0 & 0 & 0 & 0 \\
\hline Chloramphenicol & 34 & 5 & 0 & 1 & 15.0 & 7 & 3 & 0 & 0 & 30 \\
\hline Colistin ..... & 0 & 0 & 21 & 19 & 100 & 0 & 1 & 9 & 0 & 100 \\
\hline Erythromycin & 35 & 5 & 0 & 0 & 12.5 & 6 & 0 & 0 & 0 & 0 \\
\hline Gentamicin . . & 0 & 5 & 25 & 10 & 100 & 1 & 5 & 4 & 0 & 90 \\
\hline Kanamycin & 10 & 20 & 8 & 2 & 75.0 & 9 & 1 & 0 & 0 & 10 \\
\hline Nalidixic acid & 14 & 20 & 5 & 1 & 65.0 & 2 & 8 & 0 & 0 & 80 \\
\hline Novobiocin . & 38 & 2 & 0 & 0 & 5.0 & 6 & 0 & 0 & 0 & 0 \\
\hline Penicillin ... & 40 & 0 & 0 & 0 & 0 & 6 & 0 & 0 & 0 & 0 \\
\hline Poly my xin B & 0 & 6 & 28 & 6 & 100 & 0 & 8 & 2 & 0 & 100 \\
\hline Streptomycin. & 15 & 8 & 7 & 10 & 62.5 & 3 & 6 & 1 & 0 & 70 \\
\hline Tetracycline. & 5 & 13 & 14 & 8 & 87.5 & 0 & 8 & 2 & 0 & 100 \\
\hline
\end{tabular}

${ }^{a}$ Forty strains tested.

$b$ Ten strains tested. 
TABLE 11. Moles per cent of guanine plus cytosine (GC) in the DNA of five pyomelanin strains of Pseudomonas aeruginos $a^{a}$

\begin{tabular}{clc}
\hline Strain no. & Tm (C) & Moles \% GC \\
\hline 117 & $95.2^{b}$ & 65.1 \\
255 & 96.0 & 65.1 \\
256 & 96.0 & 65.1 \\
257 & 95.7 & 64.4 \\
400 & 96.0 & 65.1 \\
\hline
\end{tabular}

${ }^{a}$ As determined by R. R. Colwell (personal communication).

${ }^{b}$ Average of two determinations.

become "black" in old cultures. Jordan (23) who observed black pigment formation in old agar and gelatin cultures of some vigorous pyocyanin-producing cultures, concluded that "the black pigment is, in fact, due to the oxidation of the pyocyanin" because "the culture of $B$. pyocyaneus in tyrosine, which was kept in the dark, contained only pyocyanin and had no trace of black pigment at the end of 113 days." In another case, a pyomelanin-producing strain, $P$. aeruginosa var. erythrogenes NCTC 6749 , was labeled as a pyorubin-producing strain. Although NCTC 6749 (KM 760) is able to produce a water-soluble red pigment, pyorubin, on certain kinds of amino acid media free from tyrosine and phenylalanine, pyomelanin production predominates on the peptone-containing media specified for pigment production by the species. Therefore H. L. Schütze, who deposited this strain at the NCTC (see Catalogue of Strains, American Type Culture Collection, 9th ed. Rockville, Md., 1970), might have misidentified pyomelanin as pyorubin.

The occurrence of pyomelanin-producing strains among the $P$. aeruginosa strains encountered from clinical specimens appears to be less than 3\% (4). As shown in Table 12, they were isolated most frequently from urine and in some cases from blood, spinal fluid, pleural fluid, peritoneal fluid, sputum, ear swab, and wound swab. The ability of these strains to be associated with disease does not seem to exceed that of the apyomelanin strains of this species. They are also potentially pathogenic and able to cause a fatal infection in human cases where a lowered defense mechanism exists $(20,21$, 30). In some cases, particularly in urinary tract infection, pyomelanin-producing strains appear at some time during the course of $P$. aeruginosa infection and then disappear while the $P$. aeruginosa infection still remains. How this comes about is unknown. The natural habitat
TABLE 12. Sources of isolation of melanogenic strains of Pseudomonas aeruginosa

\begin{tabular}{|c|c|c|}
\hline Source & Present study & Elston, 1968 \\
\hline Urine & $.26^{a}$ & $7(372)$ \\
\hline Sputum $^{b}$ & .6 & $4(197)$ \\
\hline Wound and ulcer ... & .. 3 & $2(79)$ \\
\hline Blood ............ & 1 & $0(1)$ \\
\hline Perforated appendix . . . . . & . 1 & - \\
\hline Abscess $\ldots \ldots \ldots \ldots$ & $\ldots 0$ & $1(42)$ \\
\hline Pleural fluid . . . . . . . & $\ldots 0$ & $1(1)$ \\
\hline Ear swab $\ldots \ldots \ldots \ldots$ & $\ldots 0$ & $1(8)$ \\
\hline Unknown clinical specimens & is $\ldots 3$ & - \\
\hline Total & 40 & $16(700)$ \\
\hline
\end{tabular}

${ }^{a}$ Values indicate the number of melanogenic strains isolated. Values in parentheses indicate the total number of $P$. aeruginosa strains examined by Elston, 1968.

${ }^{b}$ Including tracheal secretion.

of pyomelanin-producing strains of $P$. aeruginosa is also unknown. The relationship between antibiotic treatment and pyomelanogenic mutation could not be verified. The mutation of an apyomelanin to a pyomelanin-producing strain in vitro has not yet been observed, whereas the reverse has been reported $(20,21)$.

Three prominent characteristics of pyomelanin-producing strains of $P$. aeruginosa are: (i) the ability to convert tyrosine or phenylalanine to a water-soluble brown pigment, pyomelanin, via a diffusible red substance if tyrosine or phenylalanine is present in an appropriate medium. Various peptone media, not supplemented with tyrosine, and certain amino acid media supplemented with $0.1 \%$ L-tyrosine or L-phenylalanine are suitable for demonstrating pyomelanin production by these strains; (ii) lack of pyomelanin production from tyrosine in carbohydrate-ammonium salt media which support luxuriant growth of the organism; and (iii) inability to use tyrosine as a sole source of carbon and nitrogen, whereas the neotype and most apyomelanin strains grow and produce pyocyanin with tyrosine as the sole source of carbon and nitrogen. These are possibly the reasons why Lysenko (29), who often observed soluble brown pigment on beef extract peptone agar, could not detect melanin in a chemically defined tyrosine medium incubated at $28 \mathrm{C}$ for 7 days.

Mann (32), who recently studied the tyrosine metabolism of Habs' 12 melanogenic strains of $P$. aeruginosa, found that the enzyme tyrosinase was never detected, that the brown pigment developed from accumulated homogentisic acid through labile red pigment, and that the 
isolated melanin had no identity with authentic DOPA melanin. At this time it is not known whether the brown pigment from tyrosine produced by certain strains of $P$. alcaligenes and $P$. maltophilia can be synthesized by the same mechanism as for pyomelanin.

Most of the pyomelanogenic $P$. aeruginosa strains, regardless of their pyocyanin production, can easily be identified by the critieria described by Hugh (17). As shown in Table 5, however, some pyomelanin strains are negative in certain reactions useful for the identification of $P$. aeruginosa. For example, the apyocyanogenic strain KM 439 failed to produce acid from glucose in the open tube of OF medium, and strain KM 658 did not produce 2-ketogluconate or arginine dihydrolase. Furthermore, some pyomelanin strains are reluctant to produce acid in open tubes of OF media containing galactose, mannose, melibiose, or xylose. If such a defective strain is encountered in clinical specimens, flagellar morphology and other physiological and biochemical characters, including pyocyanin or pyoverdin production, or both, have to be carefully examined to identify it as a strain of $P$. aeruginosa.

There are no significant differences in moles per cent guanine plus cytosine among the five strains tested. Data concerning DNA base composition in the genus Pseudomonas are available (31).

\section{ACKNOWLEDGMENTS}

This report is dedicated to Shinobu Osawa and Emiko Inoue, who laid the foundation for this work.

This investigation was supported by Scientific Research grant no. 70028 from the Ministry of Education, Japan.

The senior author expresses her deep appreciation to R. Hugh for his help, encouragement, and advice which made this work possible from its inception. The generosity of those who supplied important bacterial strains and the valuable technical assistance of $H$. Kato, T. Soejima, and M. Ikeda are also acknowledged. R. R. Colwell's assistance in making the moles per cent guanine plus cytosine GC determinations is greatly appreciated.

\section{ADDENDUM}

After the manuscript had been prepared the following report came to the author's attention: Liu, P. V. 1969. Changes in somatic antigens of Pseudomonas aeruginosa induced by bacteriophages. $\mathrm{J}$. Infec. Dis. 119:237--245. In this report, Liu stated that the gain of brown pigment-producing ability was frequently observed among seroty pic convertants of $P$. aeruginosa induced by certain bacteriophages.

\section{LITERATURE CITED}

1. Arai, T., M. Otake, S. Enomoto, S. Goto, and S. Kuwahara. 1970. Determination of Pseudomonas aeruginosa by biochemical test methods. II. Acylamidase test, a modified biochemical test for the identification of Pseudomonas aeruginosa. Jap. J. Microbiol. 14:279-284.

2. Carlquist, P. R. 1956. A biochemical test for separating paracolon groups, J. Bacteriol. $71: 339-341$.

3. Cassin. 1902. Observation d'un sujet chez qui fut trouvé le Bacille pyocyanique mélanogène. Ann. Inst. Pasteur 16: 327-330.

4. Elliott, R. P. 1958. Some properties of pyoverdine, the water-soluble fluorescent pigment of the pseudomonads. Appl. Microbiol. 6:241-246.

5. Elston, H. R. 1968. Melanogenic strains of Pseudomonas aeruginosa in biological specimens. Amer. J. Med. Technol. 34:189-194.

6. Ewing, W. H., B. R. Davis, and R. W. Reavis. 1957. Phenylalanine and malonate media and their use in enteric bacteriology. Publ. Health Lab. 15:153.

7. Ewing, W. H., and J. G. Johnson. 1960. The differentiation of Aeromonas and C27 cultures from Enterobacteriaceae. Int. Bull. Bacteriol. Nomencl. Taxon. 10:223-230.

8. Gadebusch, H. H., and S. Gabriel, 1956. Modified stable Kovacs' reagent for the detection of indole. Amer. J. Clin. Pathol. 26:1373-1375.

9. Gessard, C. 1898. Sur une propriété nouvelle du Bacille pyocyanique. C. R. Seances Soc. Biol. Filiales 50:1033-1035.

10. Gessard, C. 1901. Variété mélanogène du Bacille pyocyanique. Ann. Inst. Pasteur 15:81 7-831.

11. Gessard, C. 1920. D'identification des germes pyocyaniques. Ann. Inst. Pasteur 34:88-97.

12. Gessard, C. 1925. Bacille pyocyanoides de la variété mélanogène. C. R. H. Acad. Sci. 180:972-974.

13. Goto, S., and S. Enomoto, 1970. Nalidixic acid cetrimide agar-a new selective plating medium for the selective isolation of Pseudomonas aeruginosa. Jap. J. Microbiol. 14:65-72.

14. Habs, H., and M. Habs. 1968. Ueber das thermostabile Antigen der melaninbildenden Stämme von Pseudomonas aeruginosa. Zentralbl. Bakteriol. Parasitent. Infektionskr. Hyg. Abt. Orig. 208:283-288.

15. Haynes, W. C. 1951. Pseudomonas aeruginosa-its characterization and identification. J. Gen. Microbiol. 5:939-950.

16. Haynes, W. C., and W. H. Burkholder. 1957. Genus Pseudomonas Migula, 1894, p. 89-152. In Bergey's manual of determinative bacteriology, 7 th ed. The Williams \& Wilkins Co., Baltimore.

17. Hugh, R. 1970. Pseudomonas and Aeromonas, p. 175-190. In J. E. Blair, E. H. Lennette, and J. P. 
Truant (ed.), Manual of clinical microbiology. American Society for Microbiology, Bethesda, Md.

18. Hugh, R., and E. Leifson. 1953. The taxonomic significance of fermentative versus oxidative metabolism of carbohydrates by various gram negative bacteria. J. Bacteriol. 66:24-26.

19. Hugh, R., and R. Reese, 1967. Designation of the type strain for Bacterium anitratum Schaub and Hauber 1948. Int. J. Syst. Bacteriol. 17:245-254.

20. Inoue, E. 1955. Chloramphenicol resistant strain of Pseudomonas aeruginosa. (in Japanese). Jap. J. Bacteriol. 10:70.

21. Inoue, E. 1961. Studies on mutation of Pseudomonas aeruginosa. J. Amer. Med. Women's Ass. 16:858-860.

22. Jessen, O. 1965. Pseudomonas aeruginosa and other green fluorescent pseudomonads. A taxonomic study. Munksgaard, Copenhagen.

23. Jordan, E. O. 1899. Bacillus pyocyaneus and its pigments. J. Exp. Med. 4:627-647.

24. King, E. O. 1964. The identification of unusual pathogenic gram negative bacteria. National Communicable Disease Center, Atlanta, Ga.

25. King, E. O., M. K. Ward, and D. E. Raney. 1954. Two simple media for the demonstration of pyocyanin and fluorescin. J. Lab. Clin. Med. 44:301-307.

26. Leifson, E. 1951. Staining, shape, and arrangement of bacterial flagella. J. Bacteriol. 62:377-389.

27. Leifson, E. 1960. Atlas of bacterial flagellation. Academic Press Inc., New York and London.

28. Liu, P. V. 1962. Nonmotile varieties of Pseudomonas aeruginosa producing melaninlike pigment. J. Bacteriol. 84:378.

29. Lysenko, O. 1961. Pseudomonas. An attempt at a general classification. J. Gen. Microbiol. 25:379-408.

30. Maeda, R. 1956. Presentation of C.P.C. A case of septicemia due to Pseudomonas aeruginosa with monilliasis. (in Japanese). J. Kansai Med. Sch. 8:55-62.

31. Mandel, M. 1966. Deoxyribonucleic acid base composition in the genus Pseudomonas. J. Gen. Microbiol. 43:273-292.
32. Mann, S. 1969. Ueber melaninbildende Stämme von Pseudomonas aeruginosa. Arch. Mikrobiol. 65:359-379.

33. M $\phi$ ller, V. 1955. Simplified tests for some amino acid decarboxylases and for the arginine dihydrolase system. Acta Pathol. Microbiol. Scand. 36:158-172.

34. Osawa, S., E. Yabuuchi, Y. Narano, M. Nakata, Y. Kosono, K. Takashina, and T. Tanabe. 1963. Pigment production by Pseudomonas aeruginosa on glutamic acid medium and gel filtration of the culture fluid filtrate. Jap. J. Microbiol. 7:87-95.

35. Pickett, M. J., and M. M. Pedersen. 1970. Characterization of saccharoly tic nonfermentative bacteria associated with man. Can. J. Microbiol. 16:351-362.

36. Radais. 1897. Sur une nouvelle race de Bacille pyocyanique. C. R. Seances Soc. Biol. Filiales 49:808-809.

37. Shewan, J. M., and W. C. Haynes. 1967. Report of the subcommittee on Pseudomonas and related organisms (1962-1966). Int. J. Syst. Bacteriol. 17:255-259.

38. Sierra, G. 1957. A simple method for the detection of lipolytic activity of micro-organisms and some observations on the influence of the contact between cells and fatty substances. Antonie van Leeuwenhoek J. Microbiol. Serol. 23:15-22.

39. Simon, R. D. 1956. The use of fermentation reactions and pigment production to differentiate between types of Pseudomonas pyocyanea and other Pseudomonas species, especially fluorescens. Brit. J. Exp. Pathol. 37:494-499.

40. Stanier, R. Y., N. J. Palleroni, and M. Doudoroff. 1966. The aerobic pseudomonads: a taxonomic study. J. Gen. Microbiol. 43:159-271.

41. Takashina, K. 1965. Studies on Pseudomonas aeruginosa: effects of amino acids on the production of fluorescence II fraction. J. Kansai Med. Sch. 17:326-337.

42. Yabuuchi, E. 1970. p. 581-582. In H. Iizuka and T. Hasegawa (ed.) Proceedings of the First International Conference on Culture Collections. University of Tokyo Press, Tokyo. 